\title{
Okul çocuklarında inmemiş testis ve enürezis prevalansı: Prospektif epidemiyolojik kesitsel bölgesel çalışma
}

\section{Prevalence of undescended testis and enuresis in school-aged children: Prospective epidemiological cross-sectional regional study}

\author{
(1) Ali Gül, (1) Ergün Sönmezgöz \\ 'Tokat Gaziosmanpaşa Üniversitesi Tıp Fakültesi, Pediatri Anabilim Dalı, Tokat, Turkey
}

\section{Özet}

Amaç: İnmemiş testis ve enürezis, çocukluk çağında sık rastlanan sağlık sorunları olup zamanında tanı ve tedavilerinin yapılması gelecekteki komplikasyonların önlenmesi açısından büyük öneme sahiptir. Biz de bu çalışmada inmemiş testis ve enürezise dikkat çekerek okul çocuklarındaki prevalanslarını belirlemeyi amaçladık.

Gereç ve Yöntem: Bu kesitsel epidemiyolojik çalışma Tokat il merkezi ve ilçelerindeki ilkokul ve orta öğretim okullarındaki erkek çocuklarda yapıldı. Dış genital muayeneleri inmemiş testis için yapıldı ve enürezis sorgulandı. Çocukların antropometrik ölçümleri, ailede sigara ve alkol kullanımı sorgulandı ve inmemiş testis ve enürezisle ilişkileri araştırıldı. Çalışmaya alınan çocuklar yaşa göre 6-9, 10-14 ve 15-18 şeklinde üç gruba ayrıldı.

Bulgular: Toplam 6 ile 18 yaşları arasındaki 613 erkek okul çocuğu çalışmaya dahil edildi. İnmemiş testis 8 (\%1,3), enürezis ise 116 $(\% 18,9)$ çocukta saptandı. Annelerde sigara kullanımı oranı \%17,9 iken babalarda \%80 tespit edildi. Çocukların evinde \%44,9 oranında sigara içilmekteydi. Evinde sigara içilenlerde inmemiş testis prevalansı \%2,2 iken içilmeyenlerde bu oran \%0,6 saptandı $(p=0,085)$. Evinde sigara içilenlerde enürezis prevalansı \%26,2 iken içilmeyenlerde bu oran \%13 hesaplandı $(p<0,001)$. Ayrıca $6-9$ yaş arası çocuklarda enürezis prevalansı $\% 61,8$ ile diğer yaş gruplarından yüksekti $(p<0,001)$.

Sonuç: Tanı almamış inmemiş testise okul çağı çocuklarında halen rastlanmaktadır. Geç kalınmasının malignensi ve infertilite gibi ciddi sonuçları olmasından koruyucu hekimlikte ciddiye alınması için çalışmalar yürütülmelidir. Enürezis erkeklerde sıkça rastlanmakta ve psikososyal gelişim ve akademik başarıdaki olumsuz etkilerinin önlenmesi için ailelerin tıbbi yardım almaları üstünde durulmalıdır. Evde sigara içilmesi erkek çocuklarda enürezis sıklığını arttırabilir.

Anahtar Sözcükler: Alkol; enürezis; inmemiş testis; okul çocukları; sigara.

\begin{abstract}
Introduction: Undescended testis and enuresis are frequently seen and important health problem for children and their families. They could lead to serious complications in advanced aged children. In this study, we aimed to determine the prevalence of undescended testis and enuresis in school-aged boys.

Methods: This cross-sectional epidemiological study was performed with boys in the province and districts of Tokat province. External genital examinations were performed for undescended testis and enuresis was asked. Anthropometric measurements of children, smoking and alcohol dinking in the family were questioned and that's relationships with undescended testis and enuresis were investigated. Children were divided into three groups as 6-9, 10-14 and 15-18 ages.

Results: A total of 613 male school-aged children between 6 and 18 years aged were included in the study. Undescended testis was detected in 8 (1.3\%) and enuresis in $116(18.9 \%)$ children. The rate of smoking in mothers was $17.9 \%$ and $80 \%$ in fathers. The rate of smoking in home was $44.9 \%$. The prevalence of undescended testis was found to be $2.2 \%$ in children of smoked home and $0.6 \%$ in children of non-smoked home ( $p=0.085)$. The prevalence of enuresis was $26.2 \%$ in children of smoked home and $13 \%$ in children of non-smoked home $(p<0.001)$. In addition, the prevalence of enuresis in children aged 6 to 9 years was $61.8 \%$, and was higher than other age groups $(p<0.001)$.

Discussion and Conclusion: Undiagnosed undescended testes are still present in school-aged children. Since the delay of diagnosis may cause serious consequences such as malignancy and infertility, extra efforts should be made to be taken into account in preventive medicine. Enuresis is frequently encountered in school-aged boys. In order to prevent the its negative effects on psychosocial development and academic success, it should be emphasized that their families should receive medical support. Smoking at home by parents may increase the frequency of enuresis in school-aged boys.

Keywords: Alcohol; enuresis; undescended testis; school-aged children; smoking.
\end{abstract}


inmemiş testis, çocukluk çağında sık rastlanan bir patoloji olması nedeniyle çocuk sağlığıyla ilgilenen hekimlerce iyi bilinmesi gereken bir durumdur. En sık görülen dış genital organ hastalığı olan inmemiş testis ile ilgili klasik bilgi termde doğan her 100 erkek çocuktan 3'ünde görülmesi ve doğum sonrası 3 ay içinde olguların \%70-77'sinin testislerinin skrotuma inmesi ve oranın 1 yaş civarında \%1'ler seviyesine gerilemesi şeklindedir. ${ }^{[1]}$ Düşük doğum ağırlığı, prematüre doğum ve gebelik yaşı için küçük olmak inmemiş testis için bilinen risk faktörleridir. ${ }^{[2]}$ İnmemiş testis görülme oranları bölgesel farklılıklar göstermektedir. Danimarka'da yenidoğanlarda inmemiş testis görülme sıklığı \%2,75 iken, bu oran İngiltere'de $\% 5,9$ ve Kore'de \%7,26 olarak saptanmıştır. ${ }^{[3-5]}$

Enürezis, organik nedenler ekarte edildikten sonra, ayda en az bir kez olmak üzere aralıklarla, uyku sırasında altını ıslatma olarak tanımlanır. ${ }^{[6]}$ Enürezis, hem çocukların hem de ailelerin çektiği acılar açısından çoğu zaman değer verilmeyerek hafife alınan fakat çocuklarda sık görülen bir durumdur. Önceki çaIışmalar prevalans oranını \%9 ile 12 arasında bildirmiştir. Okul çağındaki çocuklarda yaşam kalitesi üzerine etkisinden dolayı önemli bir sağlık sorunudur.

İnmemiş testisin zamanında tanı ve tedavisinin yapılması, çocukların gelecekteki fertilite potansiyeli ve testis kaynaklı tümörler açısından büyük öneme sahiptir. Çocukluk ve adolesan çağda inmemiş testis ve enürezisin görülme oranlarına ait veriler farklı bölgelerde yapılmış çalışmalara aittir. Bu çalışmamızda Tokat ilindeki okul çağı erkek çocuklarında inmemiş testis ve enürezis oranlarını saptamayı ve halen tanı gecikmelerinin olduğuna dikkat çekmeyi amaçladık.

\section{Gereç ve Yöntem}

Tokat II Milli Eğitim Müdürlüğü 2013-2014 eğitim-öğretim yıIına ait verilere göre Tokat il merkezi ve ilçeleri ile bunlara bağlı köylerdeki okullar belirlendi. Araştırmaya dahil edilecek erkek öğrenci sayısı ve her okuldan araştırmaya alınacak küme sayısı il merkezi ve ilçelerdeki ilkokul, ortaokul ve liselerdeki öğrenci sayıları, cinsiyet ve yaş grupları dikkate alınarak çok tabakalı orantılı küme örnekleme yöntemi ile belirlendi. Bu kesitsel epidemiyolojik çalışma Nisan 2014 ile Haziran 2014 tarihleri arasında yürütüldü. Toplamda 613 okul çağında erkek çocuk çalışmaya dahil edildi. Enürezis için hipospadias, böbrek anomalisi, vezikoüreteral reflü tekrarlayan idrar yolu enfeksiyonu, mental retardasyon ve diyabet hastalık öyküsü dışlama kriteri olarak belirlendi. Tüm çocuklar kendi okullarında hazırlanan uygun bir muayene odasında, oda sıcaklığında, bir Çocuk Sağlığı ve Hastalıkları uzmanı tarafından muayene edildi. Hastaların kan basınçları, boy ve vücut ağırlıkları ölçüldü. VKI yaş ve cinsiyete göre 95. persentildeki değer ve üzeri obez, 85-94 persentildekiler fazla kilolu (overweight), 5 persentil altındakiler zayıf ve VKi 5-84 persentilde olanlar normal olarak tanımlandı. Çalışmaya alınan çocuklar yaşa göre 6-9, 10-13 ve 14-18 şeklinde üç gruba ayrıldı. Muayene sırasında öğrencilerin testislerinin skrotuma inip inmediğine bakıldı. Ailede alkol ve sigara içimi ve çocukta enürezis sorgulandı, kırsal ve kentsel yerleşim yeri kayıt edildi. Enürezis sıklığı, ayda 1-3 defa, haftada 1-6 defa ve günde bir ve üzeri olmak üzere üç grup olarak kayıt edildi.

Çalışma için Gaziosmanpaşa Üniversitesi Tıp Fakültesi Etik Kurulu'ndan 16-KAEK-051 numarası ile etik kurul onamı alındı. Tokat II Milli Eğitim Müdürlüğü'nden gerekli izin alındı. Çalışmaya dahil edilen çocukların velilerine (genellikle anne veya baba) sınıf öğretmenleri aracılığıyla bilgilendirme broşürü gönderildi ve onam formu imzalatıldı.

\section{İstatistiksel analiz}

Elde edilen veriler için ortalama ve standart sapma yada sayı ve yüzde kullanıldı. Nicel değişkenlerde gruplar arası karşılaştırmalarda varsayımlar yerine geldiğinde iki ortalama arasındaki farkın önemlilik testi yada tek yönlü varyans analizi kullanıldı. Nitel değişkenlerin gruplar arası karşılaştırmasında Ki-kare testi kullanıldı. $p<0.05$ değeri istatistiksel önem olarak kabul edildi. Verilerin istatistiksel analizi SPSS 19 (IBM SPSS Statistics 19, SPSS Inc., Somers, NY, USA) programı kullanılarak yapıldı.

\section{Bulgular}

Çalışmaya 6 ile 18 yaş arası 613 erkek çocuk dahil edildi. Yaş ortalaması $11,80 \pm 3,36$ yıl olarak saptandı. Çalışma gurubunun karakteristik özelliklerinin dağılımı Tablo 1'de özetlenmiştir.

İnmemiş testis $8(\% 1,3)$ çocukta tespit edildi. Enürezis ise 116 $(\% 18,9)$ çocukta saptandı. Çalışma gurubunun demografik verilerinin dağılımı Tablo 2'de gösterilmiş̧ir. İnmemiş testis tespit edilen çocukların ortalama yaşı $12,25 \pm 3,06$ yıl iken olmayanların yaş ortalaması $11,79 \pm 3,36$ saptandı $(p=0,702)$. Karakteristik nicel verilerin inmemiş testise göre dağılımı Tablo 3'te gösterilmiştir.

Evinde sigara içilenlerde inmemiş testis prevalansı \%2,2 iken içilmeyenlerde bu oran \%0,6 saptandı ve bu fark için istatistiksel anlamlıığa yakın $p$ değeri hesaplandı $(p=0,085)$. Diğer taraftan inmemiş testisin vücut ağırlığı durumuna göre dağılımında anlamlı istatistiksel fark tespit edilmedi $(p=0,567)$. İnmemiş testise göre nitel demografik ve karakteristik verilerin dağılımı Tablo 4'te özetlenmiştir.

Enürezis çalışma gurubundan $116(\% 18,9)$ çocukta tespit edildi (Tablo 2). Evinde sigara içilen çocuklarda enürezis prevalansı $\% 26,2$ iken içilmeyenlerde $\% 13$ olarak hesaplandı $(p<0,001)$.

\begin{tabular}{lccc|}
$\begin{array}{l}\text { Tablo 1. Çalışma gurubunun nicel karakteristik verilerin } \\
\text { dağılımı }\end{array}$ & n & Ort. \pm SS & $\begin{array}{c}\text { Ortanca } \\
\text { (Min.-Maks.) }\end{array}$ \\
\hline Değişkenler & & & \\
\hline & 613 & $11,80 \pm 3,36$ & $12(6-18)$ \\
Yaş & 613 & $149,12 \pm 19,11$ & $148(103-196)$ \\
Boy (cm) & 613 & $44,13 \pm 17,57$ & $40,7(17-130)$ \\
Vücut ağırlığı (kg) & 613 & $19,02 \pm 3,76$ & $18,31(9,72-41,97)$ \\
VKi (kg/m²) & 613 & $107,49 \pm 16$ & $110(0-150)$ \\
Sistolik kan basıncı & 613 & $68,56 \pm 12,05$ & $70(0-120)$ \\
Diyastolik kan basıncı & & &
\end{tabular}

Ort.: Ortalama; SS: Standart sapma; Min. Minimum; Maks: Maksimum; VKi: Vücut kitle indeksi. 
Tablo 2. Çalışma gurubunun demografik ve klinik verilerinin dağılımı

\begin{tabular}{|c|c|c|}
\hline & $\mathbf{n}$ & $\%$ \\
\hline İnmemiş testis & 8 & 1,3 \\
\hline Enürezis & 116 & 18,9 \\
\hline \multicolumn{3}{|l|}{ Enürezis sıklığı } \\
\hline Ayda 1-3 defa & 96 & 82,9 \\
\hline Haftada 1-6 defa & 14 & 12,2 \\
\hline Günde bir ve üzeri & 4 & 4,9 \\
\hline \multicolumn{3}{|l|}{ Yaş grubu } \\
\hline 6-9 & 170 & 27,7 \\
\hline $10-14$ & 298 & 48,6 \\
\hline 15-18 & 145 & 23,7 \\
\hline \multicolumn{3}{|l|}{ VKI durumu } \\
\hline Zayıf & 28 & 4,6 \\
\hline Normal & 484 & 79,0 \\
\hline Fazla kilolu & 49 & 8,0 \\
\hline Obez & 52 & 8,5 \\
\hline \multicolumn{3}{|l|}{ Yerleşim yeri } \\
\hline Kent & 478 & 78,0 \\
\hline Kırsal & 135 & 22,0 \\
\hline Evde sigara içimi & 275 & 44,9 \\
\hline \multicolumn{3}{|l|}{ Anne sigara içimi } \\
\hline Evet & 110 & 17,9 \\
\hline Bırakmış & 33 & 5,4 \\
\hline Hayır & 470 & 76,7 \\
\hline \multicolumn{3}{|l|}{ Baba sigara içimi } \\
\hline Evet & 522 & 80,2 \\
\hline Bırakmış & 69 & 11,3 \\
\hline Hayır & 52 & 8,5 \\
\hline Anne alkol alımı & 9 & 1,4 \\
\hline Baba alkol alımı & 40 & 6,6 \\
\hline
\end{tabular}

Ayrıca 6-9 yaş arası çocuklarda enürezis prevalansı $\% 61,8$ ile diğer yaş gruplarından yüksekti $(p<0,001)$. Demografik ve karakteristik nitel verilerin enürezise göre dağılımı Tablo 4'te gösterilmiştir.

\section{Tartışma}

Ülkemizde okul öncesi ve ilköğretim okullarına devam eden erkek öğrenciler arasında dış genital organ anomalilerini tespit etmeye yönelik birçok çalışma yapılmıştır. Bu çalışmalar da göstermiştir ki, okul çağındaki çocuklarda bile tespiti yapılamamış ve tedavisi gecikmiş birçok çocuk bulunmaktadır. Ankara'da 1980 yılında inmemiş testis oranı \%3,7 olarak saptanmış, ${ }^{[7]}$ Köroğlu ve ark. Türkiye'deki dış genital anomalilerin sıklığı konusunda (0-16 yaşlar için) en geniş kapsamlı çalışmayı 1996'da yapmış ve inmemiş testis oranını \%2,5 olarak rapor etmişlerdir. ${ }^{[8]}$ Çocukluk çağı inmemiş testis prevalansı, 0-18 yaşları arasındaki tüm İsveç doğumlu erkek çocuklarda
Tablo 3. İnmemiş testise göre nicel karakteristik verilerin dağılımı

\begin{tabular}{lccc} 
& \multicolumn{3}{c}{ Inmemiş testis (n=8) } \\
\cline { 2 - 4 } & $\begin{array}{c}\text { Var } \\
\text { (Ort. } \pm \text { SS) }\end{array}$ & $\begin{array}{c}\text { Yok } \\
\text { (Ort. } \pm \text { SS) }\end{array}$ & p \\
\hline Yaş & $12,25 \pm 3,06$ & $11,79 \pm 3,36$ & 0,702 \\
Boy (cm) & $151,13 \pm 18,06$ & $149,09 \pm 19,13$ & 0,765 \\
Vücut ağırlığı (kg) & $44,21 \pm 19,42$ & $44,13 \pm 17,56$ & 0,989 \\
Vücut kitle indeksi $\left(\mathrm{kg} / \mathrm{m}^{2}\right)$ & $18,42 \pm 4,2$ & $19,03 \pm 3,76$ & 0,648 \\
Sistolik kan basıncı & $108,75 \pm 13,56$ & $107,47 \pm 16,03$ & 0,822 \\
Diyastolik kan basıncı & $72,5 \pm 8,86$ & $68,5 \pm 12,08$ & 0,352 \\
\hline Ort.: Ortalama; SS: Standart sapma; Min.: VKi: Vücut kitle indeksi. Iki ortalama \\
arasındaki farkın önemlilik testi kullanıldı. & & \\
\end{tabular}

\%1,8 olarak yayınlanmıştır. ${ }^{[9]}$ New York'ta bir hastanedeki doğan erkek bebeklerin \%3,7"sinin inmemiş testisli oldukları ve 3. aydaki prevalansın $\% 1,00^{\prime}$ a gerilediği rapor edilmiş, normal kilo ve term doğan bebeklere göre düşük doğum ağırlıklı veya prematüre doğanlarda inmemiş testisin düzelme ihtimalinin daha yüksek olduğu bildirilmiştir. ${ }^{[10]}$ Sırbistan'da ise iki ilkokulda yapılmış olan bir çalışmada inmemiş testis insidansı $\% 2,0$ rapor edilmiş. ${ }^{[11]}$ Orşidopeksi ameliyatlarının oranı göz önüne alınınca aslında daha yüksek olması beklenir ve bunu destekler şekilde okul taramasında prepubertal erkek çocuklarında \%7'ye varan sıklık oranları bildirilmiştir. ${ }^{[12,13]}$ Diğer taraftan Türkiye'nin kuzeybatısında kriptorşidizm ve retraktil testis prevalansı sırasıyla \%0.73 ve \%3,9 olarak bulunmuş. ${ }^{[14]}$ Bizim çalışmamızda inmemiş testis prevalansı $\% 1,3$ olarak tespit edildi. Mekanizması tam olarak açıklanmasa da bölgesel farklılıkların olabileceği savunulmuştur. ${ }^{[15]}$ Bununla birlikte, çalışmaya alınan çocuk sayısı ve yaş aralıklarındaki seçimlerin sıklıktaki bölgesel farklılıklara sebep olabileceği görüşündeyiz. ${ }^{[16,17]}$

Hamilelik sırasında maternal sigara içiciliğin düşük sperm sayıları ve yavrularda testis kanseri için bir risk faktörü olduğu öne sürülmüştür. Annenin hamilelik sırasında sigara içiminin seviyesi ve babaların gebelik sırasında sigara içimi kriptorşidizm riskinin artmasıyla ilişkili olduğu görülmüştür. ${ }^{[18]}$ Gebelikte ağır sigara içen annelerin erkek çocukları içmeyenlerin çocuklarına göre daha yüksek sıklıkta bilateral kriptorşidizme ve daha düşük inhibin-B düzeylerine sahip oldukları saptanmış. ${ }^{[18]}$ Ayrıca anormal plasental hCG üretimi cinsiyet farklılaşma bozukluklarında anahtar rol oynayabileceği görüşü ileri sürülmüştür. [19] Bizim çalışmamızda ise sigara içimi inmemiş testis sıklığını arttırmadığı belirlendi. Sigara içen anne sayısının az olmasının istatistiksel anlamlılığa etki ettiğini düşünüyoruz.

Gebelik sırasında anne alkol alımı ile çocuklarında inmemiş testis sıklığı arasında anlamlı bir ilişki bulunmadığı raporlanmış. ${ }^{[20]}$ Diğer taraftan Estors ve arkadaşları babanın alkol alımının ve sigara içmesinin inmemiş testis için 2,36 katlık bir riske sahip olduğunu raporlamışlar. ${ }^{[21]}$ Bizim çalışmamızda ise anne veya babanın alkol ve sigara içimi inmemiş testis riskini arttırmadığı tespit edildi. Ağır sigara içilmesi ve alkol tüketiminin 
Tablo 4. İnmemiş testis ve enürezise göre nitel demografik ve karakteristik verilerin dağı̆lımı

\begin{tabular}{|c|c|c|c|c|c|c|c|c|}
\hline & \multicolumn{2}{|c|}{ Toplam } & \multicolumn{3}{|c|}{ İnmemiş testis } & \multicolumn{3}{|c|}{ Enürezis } \\
\hline & $\mathbf{n}$ & $\%$ & $\mathbf{n}$ & $\%$ & $\mathbf{p}$ & $\mathbf{n}$ & $\%$ & $\mathbf{p}$ \\
\hline \multicolumn{9}{|l|}{ Yaş grubu } \\
\hline 6-9 & 170 & 27,7 & 2 & 1,2 & \multirow{3}{*}{0,985} & 105 & 61,8 & \multirow{3}{*}{$<0,001$} \\
\hline $10-14$ & 298 & 48,6 & 4 & 1,3 & & 11 & 3,7 & \\
\hline 15-18 & 145 & 23,7 & 2 & 1,4 & & 0 & 0 & \\
\hline \multicolumn{9}{|l|}{ VKİ durumu } \\
\hline Zayıf & 28 & 4,6 & 1 & 3,6 & \multirow{4}{*}{0,567} & 6 & 21,4 & \multirow{4}{*}{0,816} \\
\hline Normal & 484 & 79 & 6 & 1,2 & & 91 & 18,8 & \\
\hline Fazla Kilolu & 4 & 8 & 1 & 2 & & 11 & 22,4 & \\
\hline Obez & 52 & 8,5 & 0 & 0 & & 8 & 15,4 & \\
\hline \multicolumn{9}{|l|}{ Yerleşim yeri } \\
\hline Kent & 478 & 78 & 8 & 1,4 & \multirow{2}{*}{0,130} & 86 & 18 & \multirow{2}{*}{0,268} \\
\hline Kırsal & 135 & 22 & 0 & 0 & & 30 & 22,2 & \\
\hline \multicolumn{9}{|c|}{ Anne sigara içimi } \\
\hline Hayır & 470 & 76,7 & 5 & 1,1 & \multirow{3}{*}{0,305} & 89 & 18,9 & \multirow{2}{*}{0,993} \\
\hline Evet & 110 & 17,9 & 3 & 2,7 & & 21 & 19,1 & \\
\hline Bırakmış & 33 & 5,4 & 0 & 0 & & 6 & 18,2 & \\
\hline \multicolumn{9}{|c|}{ Baba sigara içimi } \\
\hline Hayır & 52 & 8,5 & 0 & 0 & \multirow{3}{*}{0,391} & 12 & 23,1 & \multirow{3}{*}{0,076} \\
\hline Evet & 522 & 80,2 & 8 & 1,5 & & 98 & 18,8 & \\
\hline Bırakmış & 69 & 11,3 & 0 & 0 & & 6 & 8,6 & \\
\hline \multicolumn{9}{|c|}{ Evde sigara içimi } \\
\hline Evet & 275 & 44,9 & 6 & 2,2 & \multirow{2}{*}{0,085} & 72 & 26,2 & \multirow{2}{*}{$<0,001$} \\
\hline Hayır & 338 & 55,1 & 2 & 0,6 & & 44 & 13 & \\
\hline \multicolumn{9}{|l|}{ Anne alkol alımı } \\
\hline Hayır & 604 & 98,6 & 8 & 1,3 & \multirow{2}{*}{0,728} & 113 & 18,7 & \multirow{2}{*}{0,266} \\
\hline Evet & 9 & 1,4 & 0 & 0 & & 3 & 33,3 & \\
\hline \multicolumn{9}{|l|}{ Baba alkol alımı } \\
\hline Hayır & 573 & 93,4 & 7 & 1,2 & \multirow{2}{*}{0,491} & 110 & 19,2 & \multirow{2}{*}{0,512} \\
\hline Evet & 40 & 6,6 & 1 & 2,5 & & 6 & 15 & \\
\hline \multicolumn{9}{|l|}{ Enürezis } \\
\hline Evet & 82 & 13,8 & 3 & 3,7 & & - & - & - \\
\hline Hayır & 531 & 86,2 & 5 & 0,9 & 0,177 & - & - & - \\
\hline
\end{tabular}

VKi: Vücut kitle indeksi. Ki-kare testi kullanıldı.

inmemiş testiste rol aldığı gösterilmiş olup, bizim çalışmamızda alınan sigara veya alkol miktarı sorgulanmamış olmasından dolayı etkileri görülmemiş olabilir. Diğer taraftan inmemiş testisin gelişiminde plasental disfonksiyon veya testisin içsel sorunları gibi başka sebeplerin de rol oynamasından çalışmalar arasındaki bu farklılıklar görülmüş olabilir.

Enürezis, çocuğun psikososyal gelişimini ve yaşam kalitesini etkileyen çocukluk çağının sık karşılaşılan sorunlarından biridir. Çocukta özgüven kaybına, utanç duymasına ve psikolojik başka sorunlara neden olmaktadır. Çocuklardaki prevalansı bölgesel, yaş ve cinsiyetler arası farklılıklar gösterir. Kahramanmaraş'ta 6 ile 11 yaşlardaki çocuklarda yapılan bir çalışmada erkeklerde enürezis prevalansı \%17,3 iken kızlarda $\% 9,3$ olarak tespit edilmiş. ${ }^{[22]}$ Benzer olarak erkeklerde yapılan bizim bu çalışmamızda da prevalans \%18,9 olarak saptandı. Fakat yaş gurubu göz önüne alındığında 6-9 yaşlardaki prevalansın bizim çalışmamızda çok daha yüksek olduğu görüldü. Bizim çalışmamızla benzer şekilde Ankara'da 6-7 yaş için prevalans \%45 olarak rapor edilmiştir. ${ }^{[6]}$ Ayrıca erkeklerde 7 yaşlar için \%15-22 sıklık ta bildirilmiştir. ${ }^{[6,23]}$ Enürezisin tanımlanmasındaki farklııılara bağlı sıklığın değiştiğini düşünüyoruz. Enürezis kriterleri sıkı tutulursa düşük prevalans oranının, diğer taraftan kriterler genişletilirse daha yüksek oranın tespitine sebep olabilir. Ayrıca çevresel stres faktörlerinin enürezis etyolojisinde rol oynadığı göz önüne alındığında bölgesel farklılıkların sosyoekonomik durum eşitsizliğinden kaynaklandığı düşünülebilir. Daha ileri çocukluk yaşlarında ve erişkinde enürezisin $\% 1$ oranında rastlandığı bildirilmiştir. ${ }^{[23]}$ 
Sigaranın enürezisin sıklığını arttırdığıyla ilgili çok çalışma olmamakla birlikte, maternal ağır sigara içiminin çocuklarda enürezis riskini 1.60 kat arttırdığı raporlanmıştır. ${ }^{[24]}$ Benzer şekilde bizim çalışmada da evinde sigara içilen çocuklarda enürezis sıklığı daha yüksekti. Diğer taraftan annenin sigara içimi risk olarak saptanmadı. Sigara içen anne sayısının azlığının bu sonuçta etken olduğu görüşündeyiz. Sigara gibi çevresel faktörlerin enürezisi hangi mekanizmalarla etkilediği açık değildir. Bununla birlikte, erişkinlerde idrar yollarının fonksiyonel bozuklukları sigara içmeyle ilişkilendirilmiş ve aşırı aktif mesane ve idrar kaçırma semptomlarına sebep olduğu raporlanmıştır. ${ }^{[25,26]}$ Ayrıca erişkin sigara içen kadınlarda erişkin dönemde ortaya çıkan sekonder enürezis sıklığının arttığı belirtilmiştir. ${ }^{[26]}$ Diğer taraftan enürezisin etyolojisi multifaktöriyel olup tam olarak açıklanamamıştır. Genetik, gelişimsel, ailesel, psikolojik ve çevresel faktörler, uyku bozuklukları, cinsiyet, mesane ile ilişkili faktörler enürezis gelişiminde rol oynamaktadır. ${ }^{[27]}$

Sonuç olarak tanı almamış inmemiş testise okul çağı çocuklarında halen rastlanmaktadır. Geç dönemde tespit edilmesinin testis malignensilerine ve infertiliteye sebep olması düşünüldüguünde okul dönemine kadar tanıda geç kalınması önemli bir sorundur. Tıp fakültesi çekirdek eğitiminde inmemiş testisin taranmasının koruyucu hekimlikte önemine daha çok vurgu yapılabilir. Diğer taraftan enürezis özellikle küçük yaştaki okul çocuklarının süregelen önemli bir sorunudur. Davranış bozukluğu, küçük düşme kaygısı, sosyal çekingenlik ve ileride akademik başarıda problemler yaşanması gibi sağlık sorunlarıyla ilişkilendirilmiştir. Evde sigara içilmesi erkek çocuklarda enürezis sıklığını arttırabilir. Ebeveynlerin bunu önemli bir sağlık sorunu olarak görmelerine ve tıbbi yardım almalarına dikkat çekilebilir.

Etik Komite Onay: Çalışma için Gaziosmanpaşa Üniversitesi Tıp Fakültesi Etik Kurulu'ndan 16-KAEK-051 numarası ile etik komite onayı alınmışır (16-KAEK-051).

Hasta Onamı: Yazılı hasta onamı bu çalışmaya katılan hastaların velilerinden alınmıştır.

Finansal Destek: Gaziosmanpaşa Üniversitesi Bilimsel Araştırmalar Projeleri Komisyonundan finansal destek alınmıştır.

Çıkar çatışması: Yazarlar çıkar çatışması bildirmemiştir.

\section{Kaynaklar}

1. Schneck FX, Bellinger MF. Abnormalities of the testes and scrotum and their surgical management. Campbell-Walsh Urology. 2007;4:9.

2. Akre O, Lipworth L, Cnattingius S, Sparén P, Ekbom A. Risk factor patterns for cryptorchidism and hypospadias. Epidemiology. 1999:364-9.

3. Schnack TH, Poulsen G, Myrup C, Wohlfahrt J, Melbye M. Familial coaggregation of cryptorchidism, hypospadias, and testicular germ cell cancer: a nationwide cohort study. Journal of the National Cancer Institute. 2010;102(3):187-92.

4. Acerini $C L$, Miles HL, Dunger DB, Ong KK, Hughes IA. The desc- riptive epidemiology of congenital and acquired cryptorchidism in a UK infant cohort. Archives of disease in childhood. 2009;94(11):868-72.

5. Choi H, Kim KM, Koh SK, Kim KS, Woo YN, Yoon JB, et al. A Survey of Externally Recognizable Genitourinary. Journal of Korean medical science. 1989;4(1):13-21.

6. Sarici H, Telli O, Ozgur BC, Demirbas A, Ozgur S, Karagoz MA. Prevalence of nocturnal enuresis and its influence on quality of life in school-aged children. Journal of Pediatric Urology. 2016;12(3):159.e1-.e6.

7. Remzi D, Çakmak F, Erol D. İlkokul çağındaki erkek çocuklarında dış genital organ anomalileri ve gelişim bozuklukları insidansı. Hacettepe Tıp Cerrahi Bülteni. 1980;13(3):269-73.

8. Koroglu E, Karaaslan Y, Yoneyman F, Gurvit G, Yusuf M. Ro-CODEC Çocuklarda kronik hastalıkların sıklığı taraması çalışması. Ankara, Medico-Graphics. 1996:97-100.

9. Bergbrant S, Omling E, Björk J, Hagander L. Cryptorchidism in Sweden: a nationwide study of prevalence, operative management, and complications. The Journal of pediatrics. 2018;194:197203. e6.

10. Berkowitz GS, Lapinski RH, Gazella JG, Dolgin SE, Bodian CA, Holzman IR. Prevalence and Natural History of Cryptorchidism. Pediatrics. 1993;92(1):44-9.

11. Zivkovic D, Varga J, Grebeldinger S, Dobanovacki D, Borisev V. [External genital abnormalities in male schoolchildren: an epidemiological study]. Medicinski pregled. 2004;57(5-6):275-8.

12. Virtanen HE, Cortes D, Rajpert-De Meyts E, Ritzen EM, Nordenskjold A, Skakkebaek NE, et al. Development and descent of the testis in relation to cryptorchidism. Acta paediatrica (Oslo, Norway: 1992). 2007;96(5):622-7.

13. Ghirri P, Ciulli C, Vuerich M, Cuttano A, Faraoni M, Guerrini L, et al. Incidence at birth and natural history of cryptorchidism: A study of 10,730 consecutive male infants. Journal of Endocrinological Investigation. 2002;25(8):709-15.

14. Inan M, Aydiner CY, Tokuc B, Aksu B, Ayhan S, Ayvaz S, et al. Prevalence of Cryptorchidism, Retractile Testis and Orchiopexy in School Children. Urologia Internationalis. 2008;80(2):166-71.

15. Niedzielski JK, Oszukowska E, Slowikowska-Hilczer J. Undescended testis - current trends and guidelines: a review of the literature. Archives of medical science: AMS. 2016;12(3):667-77.

16. Adayener C, Ateş F, Soydan H, Türk L, Şenkul T, Baykal K. Türkiye'de 13-15 yaş arası ergen erkek çocuklarda dış genital organ hastalığı oranları. Türk Üroloji Dergisi. 2010;36(2):155-9.

17. Davarcı M, Rifaioğlu MM, İnci M, Yalçınkaya FR, Gökçe A, Tutanç M, et al. Hatay İli 7-11 Yaş Arası Dış Genital Organ Anomali Oranları. Van Tıp Dergisi. 2012;19(3):108-11.

18. Jensen MS, Toft G, Thulstrup AM, Bonde JP, Olsen J. Cryptorchidism according to maternal gestational smoking. Epidemiology. 2007;18(2):220-5.

19. Schneuer F, Bower C, Holland A, Tasevski V, Jamieson S, Barker A, et al. Maternal first trimester serum levels of free-beta human chorionic gonadotrophin and male genital anomalies. Human Reproduction. 2016;31(8):1895-903.

20. Kjersgaard C, Arendt LH, Ernst A, Lindhard MS, Olsen J, Henriksen TB, et al. Lifestyle in pregnancy and cryptorchidism in sons: a study within two large Danish birth cohorts. Clinical epidemiology. 2018;10:311-22.

21. Estors Sastre B, Bragagnini Rodriguez $P$, Fernandez Atuan R, Delgado Alvira R, Rihuete Heras MA, Gracia Romero J. [Endocrine disrupting chemicals exposure and other parental factors in 
hypospadias and cryptorchidism etiology]. Cirugia pediatrica: organo oficial de la Sociedad Espanola de Cirugia Pediatrica. 2015;28(3):128-32.

22. Özkan K, Garipardic M, Toktamis A, Karabiber H, Sahinkanat T. Enuresis prevalence and accompanying factors in schoolchildren: a questionnaire study from southeast Anatolia. Urologia internationalis. 2004;73(2):149-55.

23. Wright A. Evidence-based assessment and management of childhood enuresis. Paediatrics and Child Health. 2008;18(12):5617.

24. Rona RJ, Li L, Chinn S. Determinants of nocturnal enuresis in Eng- land and Scotland in the'90s. Developmental Medicine \& Child Neurology. 1997;39(10):677-81.

25. Hannestad YS, Rortveit G, Daltveit AK, Hunskaar S. Are smoking and other lifestyle factors associated with female urinary incontinence? The Norwegian EPINCONT Study. BJOG: an international journal of obstetrics and gynaecology. 2003;110(3):247-54.

26. Madhu C, Enki D, Drake MJ, Hashim H. The Functional Effects of Cigarette Smoking in Women on the Lower Urinary Tract. Urologia Internationalis. 2015;95(4):478-82.

27. Alparslan N, Kostak MA. Enürezisli Çocuğa Yaklaşım. TAF Preventive Medicine Bulletin. 2012;11(5). 